\title{
Survey of optimization methods for BIW lightweight design
}

\author{
WANG Zheyun ${ }^{1,}$ a \\ ${ }^{1}$ School of Automotive Engineering, Dalian University of Technology, Dalian 116024, P.R. China
}

\begin{abstract}
The body lightweight is important to the vehicle design and development, which has become one of the main research subjects in vehicle industries and research institutes. This paper systematically expounds the background and significance of the lightweight design of automobile, and systematically expatiates the implementation method of the light weight of the vehicle from the fields of lightweight materials, body structural optimization design, molding technology and new connecting technologies. The present situation of domestic and foreign research on lightweight design is introduced at the same time. On this basis, this paper establishes the process of multidisciplinary lightweight design of vehicles, and applies a variety of simulation and modeling tools into this process. The experiment results show the effectiveness and efficiency of the method
\end{abstract}

\section{Introduction}

Energy consumption and pollutant emission is serious, and the car's energy consumption is especially large. Lightweight design can have great effect on reducing energy consumption and pollutant. At the same time, bodyin-white (BIW) lightweight can improve the performance of auto parts, i.e. brake performance security performance and so on. In this paper, it's mainly about the Lightweight design of the body-in-white.

The body was an important part to the whole vehicle. Most of the vehicle body was made up of stamping parts, which had a complex structure and was composed of many parts. The body occupies almost $60 \%$ of the investment cost, whose mass occupies about $30-40 \%$ of the whole vehicle. In no-live load condition, about $70 \%$ of the vehicle's gas consumption was expended on the vehicle body. Therefore, the body lightweight was important to the vehicle lightweight, also it was one of the main research subjects in vehicle industry [1] [2].

\section{Lightweight Design Methods}

In order to achieve the purpose of weight loss, researchers constantly explore the vehicle lightweight methods and technologies in the development of new vehicles. Although the method of weight reduction is diverse, it is generally summarized as follows.

\subsection{High-strength lightweight materials}

\subsubsection{High strength steel}

Baogang and Taigang have produced the third-generation high strength steel, with a tensile strength and ductility of $20 \%$ GPA and 30\% GPA, respectively. They have also cooperating with First Automotive Works, Shanghai Automotive Industry Corporation, China Automotive Engineering Research Institute and other units to carry out the evaluation research of applicability.

\subsubsection{Aluminum alloy}

Audi launches Audi A2, whose white body adopts the second generation ASF technology, using simple extrusion parts as far as possible and a lot of laser welding technology. The aluminum joint connection was also changed to adhesive connection. Jaguar's new XJ applies a single shell structure to steel bodies and connects parts of the body by self-piercing riveting and bonding techniques. On the basis of summing up the advantages of ASF technology and monomer construction technology, Honda and General Company have developed the Honda Insight and general Precept by giving full play to the role of aluminum alloy.

\subsubsection{Magnesium alloy}

There are more than 100 kinds of magnesium alloy parts in the strong automotive countries like Europe and North America. The three largest automotive groups in the United States, general motors, Ford and Chrysler employ more than 45, 30 and 20 magnesium alloy components, respectively. Chen from Zhejiang University studied the NVH performance of automotive magnesium alloy materials and performed an acoustic optimization design for the magnesia dashboard, which reduced the dashboard quality by $3.6 \mathrm{~kg}$ [3]. 


\subsubsection{Non-metallic materials}

Automotive fiber composites mainly include carbon fiber reinforced polymer (CFRP) and glass fiber reinforced plastic (GFRP). The density of CFRP is $1380 \mathrm{Kg} / \mathrm{m} 3$, about $1 / 6$ to $1 / 5$ of steel. Audi has introduced fiber reinforced plastic (FRP) round springs, which reduced the weight of each A4 front suspension system from $2.66 \mathrm{~kg}$ to $1.53 \mathrm{~kg}$, more than $40 \%$ weight loss than in the steel spring [4]. In March, 2013, Daimler's new GL-class SUV equipped its six-cylinder diesel engine with the world's first plastic engine bracket. Compared with the previous aluminum stent, plastic stent has a better acoustic properties and thermal insulation performance, as well as lighter quality and better carrying capacity [5].

\subsection{Body structure optimization}

Through the structural lightweight design, the corresponding material, the optimal structure and size are used in the appropriate location of the car structure, so that each part of the material can perform the maximum load and energy absorption. An optimized body structure can improve material utilization, reduce vehicle weight, reduce material costs and achieve energy saving, emission reduction, and reducing consumption at the same time.

\subsubsection{Topology optimization and size optimization}

In engineering, topology optimization and shape optimization are combined together to determine the optimum structure. In the development of new material automotive components, topology optimization method is used to obtain the structural contour of the component, and then the dimensional optimization method is used to obtain the specific structure of the component.

Zhu et.al applied the topology optimization technology into the automotive gearbox shell structure design based on variable-density method, which improves the strength, stiffness, natural frequency and control structure quality through static and dynamic topology optimization considering the constraints of the manufacturing process [6]. Zhou et.al conducted the bus body lightweight design based on topology optimization and sensitivity analysis, with a body mass reduction of $362 \mathrm{~kg}$ [7].

\subsubsection{Shape optimization}

Shi et.al used SFE-CONCEPT software to establish the model of the white body parameters and optimization of the model. The optimized model is basically unchanged in the context of the performance, with the quality of BIW reduced by $12 \mathrm{Kg}$, and a weight loss rate of $4.5 \%$ [8].

\subsubsection{Multi-objective multidisciplinary optimization}

The multi-objective optimization problem was first put forward by Pareto in 1896. He concluded the multi-objective optimization problem from the point of view of economic balance. While lightening the vehicle, the following requirements must be met: vibration, noise and ride comfort
(Noise Vibration Harshness); stiffness, strength and crashworthiness requirements of the entire vehicle; reliability, etc. Therefore, many scholars have applied the research methods of multi-objective algorithms to the design of automotive lightweight [9] [10].

After taking into consideration the dashboard collision performance and $\mathrm{NVH}$ performance and lightweight performance, Wang et.al established a multi-discipline multiobjective optimization design model [11]. Under the frontal collision condition, the vehicle occupant protection system is designed with the multi-objective optimization method to improve the vehicle occupant protection system by Gu et.al [12]. Considering the lightweight, bus stiffness and intensity, rolling safety and other factors, Su et.al carried out the multiobjective optimization design of the bus body frame and the experiments at the same time [13]. The bus body weight decreased $2.7 \%$ to ensure the vehicle body rigidity and strength performance.

\subsection{Application of new technologies}

\subsubsection{Laser tailor welded blanks}

Azuma and others have studied the formability of tailor welded blanks. The results show that the formability of tailor welded blanks is related to the orientation of welds and the main strain.

\subsubsection{Continuous variable panel technology}

Compared with TWB technology, TRB technology eliminates welding process, thus reducing production cost. In addition, the TRB plate has no welding seam, so the component has the advantages of high connection strength, good uniformity and good shock resistance. The board surface with TRB technology is smooth and beautiful, and can be widely used in automobile body outer panel. Ford Focus B column was produced by TRB technology.

\subsubsection{Tailor Rolling Tube - TRT}

TRT is a new technology formed on the basis of TRB technology and hydraulic forming technology. It can realize the strength design of parts, prolong the life of parts and simplify the production process. TRT technology can be used in the production of A, B column, sub frame and other components.

\subsubsection{Thermoforming Technology}

There were over 210 thermal forming steel production lines worldwide, and more and more models were being used in thermoforming technology. Hot forming technology is applied in the A column, B column, C column, sill, front and rear anti-collision beam, roof side beam, backplane channel and so on.

\subsubsection{Hydraulic forming and gas forming technology}


FAW and the Harbin Institute of Technology cooperated on the model of the engine sub frame. In addition, Baogang has also introduced hydraulic to form the production line and produce some prototypes.

\subsection{New connection technology}

\subsubsection{Laser welding}

It is mainly used for welding thin materials and welding speed, welding process of heat conduction, laser radiation heating surface. Surface heat through the heat transfer oriented internal diffusion by controlling the pulse width and energy, peak power and repetition frequency parameter to form the specific melting pool in the 1970s.

\subsubsection{Self-piercing riveting}

SPR technology was first applied to Audi A8, which was then subsequently applied to Jaguar, XJ, Audi, new 5 series, Audi TT and other models. The self-piercing riveting technology can not only realize the connection of the same material plate, but also realize the connection of dissimilar materials and plates with different thickness.

\subsubsection{Pressure connection technique}

At present, the pressure connection technology has been applied to Audi, A6, Passat, POLO, new Golf-5 and other models. Although the price of pressure connection is low compared to SPR technology, and the strength of the connection position is also low, which limits the application of the pressure connection technique.

\section{$3 \quad$ Multidisciplinary lightweight design process \\ optimization}

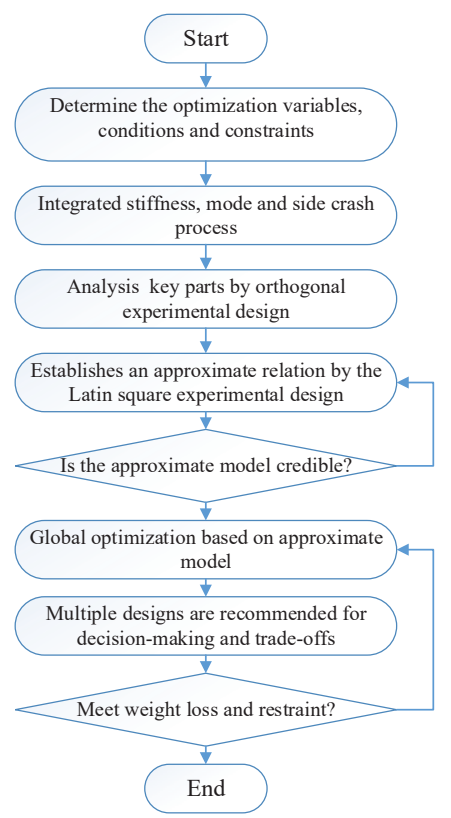

Figure 1. Flow chart of lightweight multidisciplinary optimization design.
Based on the above analysis of BIW lightweight design methods, this paper proposed a Multidisciplinary optimization lightweight design process. Fig.1 shows the flow chart of lightweight multidisciplinary design optimization for a domestic car. This chapter focuses on the design variables (factors), response and level determination. At the same time, the parametric integration of stiffness, modal and side collision is implemented by Isight, and the experimental design analysis is carried out. According to the process, for the optimization design in this paper, we must first define the calculation conditions, constraints, and determine the factors and their level. Secondly, factors and horizontal orthogonal test table by the orthogonal experimental design method of orthogonal experiment are formed. Using the orthogonal table, this paper integrates stiffness and modal, side collision calculation file by Isight and submit the calculated arch for further analysis of sample points. Global optimization algorithms are designed based on the approximate models.

\section{Simulation and modeling tools}

In our experiments, we select twenty-one parts' thickness and eleven kinds of material from the BIW design example as design variables. The design tasks considered in this case study determine these design variables step by step to minimize the weight while satisfying multidisciplinary constraints such as static stiffness, vibration characteristics, low/high speed crash, and Noise Vibration Harshness (NVH) analysis. The following table shows the optimization process for vehicle lightweight design by using different simulation modeling tools [14] [15].

Table 1. Modeling and simulation tools for BIW optimization design process

\begin{tabular}{|c|c|c|}
\hline Subject & Content & Tools \\
\hline $\begin{array}{l}\text { Finite element } \\
\text { modeling and } \\
\text { verification }\end{array}$ & $\begin{array}{l}\text { Modeling and verification of } \\
\text { BIW stiffness, modal and side } \\
\text { impact by finite element method }\end{array}$ & $\begin{array}{c}\text { Nastran } \\
\text { Pam }\end{array}$ \\
\hline $\begin{array}{l}\text { Simulation process } \\
\text { integration and } \\
\text { parameterization }\end{array}$ & $\begin{array}{l}\text { Integrated the simulation models } \\
\text { of various disciplines and } \\
\text { parameterize the input and output }\end{array}$ & Isight \\
\hline $\begin{array}{l}\text { Sampling analysis of } \\
\text { experimental design }\end{array}$ & $\begin{array}{l}\text { Design the experimental matrix } \\
\text { and analyze the key parameters } \\
\text { and sensitivities }\end{array}$ & $\begin{array}{l}\text { Isight/ } \\
\text { Nastran } \\
\text { Pam }\end{array}$ \\
\hline $\begin{array}{l}\text { Establish an } \\
\text { approximate } \\
\text { (alternative) model }\end{array}$ & $\begin{array}{l}\text { Replace the time-consuming } \\
\text { simulation in optimization by an } \\
\text { efficient and accurate } \\
\text { approximation model }\end{array}$ & Isight \\
\hline $\begin{array}{l}\text { Global } \\
\text { multidisciplinary } \\
\text { optimization }\end{array}$ & $\begin{array}{l}\text { Find the global optimal solution } \\
\text { based on the approximate model }\end{array}$ & Isight \\
\hline $\begin{array}{l}\text { Verification and } \\
\text { tradeoff of } \\
\text { optimization results }\end{array}$ & $\begin{array}{l}\text { verify the optimization results by } \\
\text { finite element, balance by } \\
\text { multiple criteria }\end{array}$ & $\begin{array}{l}\text { Nastran } \\
\text { PamCr } \\
\text { ash }\end{array}$ \\
\hline
\end{tabular}




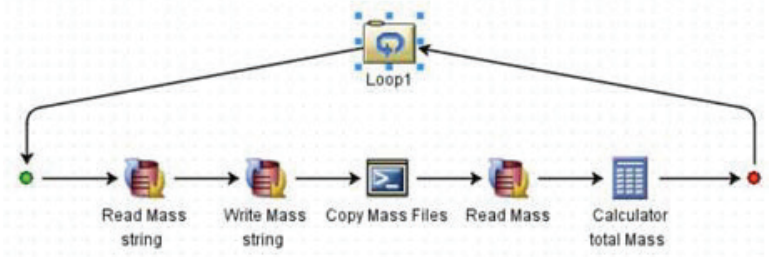

Figure 2. Flow GUI of Isight simulation platform

Fig.2 shows the Graphical User Interface (GUI) of Isight, which provides a comprehensive selection of parallelized optimization techniques that can be applied to a variety of problems. By applying the optimization methods and software, the simulation time is reduced from 8 hours to 2 hours.

\section{Conclusion and future work}

This paper systematically expounds the background and significance of the lightweight design of automobile, and systematically expatiates the implementation way of the light weight of the vehicle from the fields of lightweight materials, structural optimization design and molding technology. The present situation of domestic and foreign research on lightweight design is described at the same time. On this basis, this paper establishes a process of lightweight multidisciplinary design of white body, and applies a variety of simulation and modeling tools into this process. The experiment results show the effectiveness and efficiency of the methods.

\section{Reference}

1. A.V. Londhe. A systematic approach for weight reduction of BIW panels through optimization, SAE Technical Paper, 2010-01-0389.

2. Y.W. Lee. A Study on the improvement of the structural joint stiffness for Aluminium BIW, SAE Technical Paper, (1997). 970583.

3. Chen Xinrui, Investigation on NVH performance of automotive magnesium alloy and acoustic optimization design for magnesium dash [D], Zhejiang University, 2011.

4. Jenne, M., et al. "Improved Mechanical Preload Measurement of Bolted Joints for Light Weight Design with CFRP Components." ASME 2015 International Mechanical Engineering Congress and Exposition. American Society of Mechanical Engineers, 2015.

5. http://ae-plus.com/technology/basf-designs-plasticengine-mount-for-daimler.

6. ZHU, Jian-feng, et al. "Structural topology optimization based design of automotive transmission housing structure." Journal of Jilin University (Engineering and Technology Edition) 3 (2013): 004.

7. Wei, Z. H. O. U. "Research on the lightweight design of bus body based on topology optimization and sensitivity analysis." Journal of Hefei University of Technology (Natural Science) 4 (2013): 006.

8. Yuze, SHI Guohong CHEN Yong YANG, and JIANG Xin SONG Zhengchao. "BIW Architecture Multidisciplinary Light Weight Optimization Design." Journal of Mechanical Engineering 8 (2012): 019.

9. Karande, Prasad, and Shankar Chakraborty. "Application of multi-objective optimization on the basis of ratio analysis (MOORA) method for materials selection." Materials \& Design 37 (2012): 317-324.

10. Su, Ruiyi, Liangjin Gui, and Zijie Fan. "Multi-objective optimization for bus body with strength and rollover safety constraints based on surrogate models." Structural and Multidisciplinary Optimization 44.3 (2011): 431-441.

11. Wang, Ping, and Guangqiang Wu. "Multidisciplinary design optimization of vehicle instrument panel based on multi-objective genetic algorithm." Chinese Journal of Mechanical Engineering 26.2 (2013): 304-312.

12. Gu, Xianguang, et al. "Multiobjective optimization design for vehicle occupant restraint system under frontal impact." Structural and Multidisciplinary Optimization 47.3 (2013): 465-477.

13. Gu, Xianguang, et al. "Multiobjective optimization design for vehicle occupant restraint system under frontal impact." Structural and Multidisciplinary Optimization 47.3 (2013): 465-477.

14. Y. Qu. 2013. Stiffness evaluation method of BIW with sensitivity coefficients, SAE Technical Paper, 2013-010975.

15. Nomura, S. Murakami, H. Kuroda, K. Tanaka, R. Ramoo, P. Kosarek, M. Parthasarathy and R. Chandaroy. 2003. Improvement of BIW NVH characteristics using a concurrent design optimization approach, SAE Technical Paper, 2003-01-1596. 